\title{
BMJ
}

\section{Factors associated with mortality in Scottish patients receiving methadone in primary care: retrospective cohort study}

\author{
C McCowan, lecturer in health informatics, ${ }^{1} \mathrm{~B}$ Kidd, clinical senior lecturer in addiction psychiatry, ${ }^{2}$ \\ T Fahey, professor of primary care medicine ${ }^{1,3}$
}

${ }^{1}$ Division of Community Health Sciences, University of Dundee, Dundee DD2 4BF

${ }^{2}$ Section of Psychiatry and Behavioural Sciences, Division of Pathology and Neuroscience, University of Dundee, Ninewells Hospital and Medical School,

Dundee DD1 9SY

${ }^{3}$ Department of General Practice and Family Medicine, Division of Population Health Sciences, Royal College of Surgeons in Ireland,

Dublin 2, Ireland

Correspondence to: T Fahey tomfahey@rcsi.ie

Cite this as: BMJ 2009;338:b2225 doi:10.1136/bmj.b2225

\section{ABSTRACT}

Objective To assess predictors of mortality in a population of people prescribed methadone.

Design Retrospective cohort study.

Setting Geographically defined population in Tayside, Scotland.

Participants 2378 people prescribed and dispensed liquid methadone between January 1993 and February 2004.

Main outcome measures All cause mortality (primary outcome) and drug dependent cause specific mortality (secondary outcome) by means of Cox proportional hazards models during 12 years of follow-up. Results Overall, 181 (8\%) people died. Overuse of methadone (adjusted hazard ratio 1.67, $95 \%$ confidence interval 1.05 to 2.67), history of psychiatric admission $(2.47,1.67$ to 3.66$)$, and increasing comorbidity measured as Charlson index $\geq 3(1.20,1.15$ to 1.26$)$ were all associated with an increase in all cause mortality. Longer duration of use (adjusted hazard ratio 0.95, 0.94 to 0.96$)$, history of having urine tested $(0.33,0.22$ to 0.49), and increasing time since last filled prescription were protective in relation to all cause mortality. Drug dependence was identified as the principal cause of death in 60 (33\%) people. History of psychiatric admission was significantly associated with drug dependent death (adjusted hazard ratio 2.41, 1.25 to $4.64)$, as was history of prescription of benzodiazepines $(4.35,1.32$ to 14.30$)$.

Conclusions Important elements of care in provision of methadone maintenance treatment are likely to influence, or be a marker for, a person's risk of death.

\section{INTRODUCTION}

Drug misuse is a major public health problem throughout the United Kingdom and elsewhere. In Scotland, 10798 people presented to drug misuse agencies in 2002, half of whom were in their 20s. ${ }^{12}$ Similarly, in the United States, more than three million people are estimated to have used heroin, and 200000 people are estimated to be engaged with opiate treatment programmes. ${ }^{3}$ Drug misusers have an annual mortality six times higher than that for a general, age matched population, and more than two thirds of these deaths are due to drug overdoses. ${ }^{4}$

To combat this public health problem, methadone maintenance programmes have been started on the basis of evidence from randomised trials that methadone decreases illicit drug use, reduces injecting behaviour leading to a decrease in transmission of viral infections such as HIV and hepatitis, reduces the risk of opioid related deaths, improves physical and mental health, and is associated with a decrease in criminal activity. ${ }^{5-7}$ In the UK, methadone treatment for heroin addiction is largely provided by general practitioners - the "British system" - and prescribing of methadone in primary care substantially increased throughout the 1990 s. $^{89}$ The central ethos of this approach is one of harm minimisation, and other countries are expanding provision of methadone treatment into primary care in a similar way. ${ }^{310}$

However, treatment with methadone in primary care has been described as a "double edged sword" because methadone itself is associated with drug related deaths. ${ }^{11}$ A confidential inquiry into methadone related deaths carried out in Scotland in 2000 showed an $18 \%$ year on year increase in the number of prescriptions for methadone since $1996{ }^{12}$ Fifty six drug related deaths took place in 2000 and were referred to the inquiry; in $30(54 \%)$ cases, methadone was cited on the death certificate. ${ }^{12}$ Because of the annual increase in the number of prescriptions for methadone, although the proportion of methadone related deaths is declining, methadone related deaths still represent an important public health problem. ${ }^{912} 13$ Methadone related deaths seem to be due to an interaction of patient related and organisational factors: drug dosing, concurrent use of other drugs, and deficiencies in the monitoring and delivery of methadone care programmes. ${ }^{714}$

Because of the risks and benefits of methadone treatment in the community, guidance on prescription, monitoring, and dispensing arrangements for methadone has evolved alongside a postgraduate training programme sponsored by the Royal College of General Practitioners Substance Misuse Unit. ${ }^{15}$ Formal 


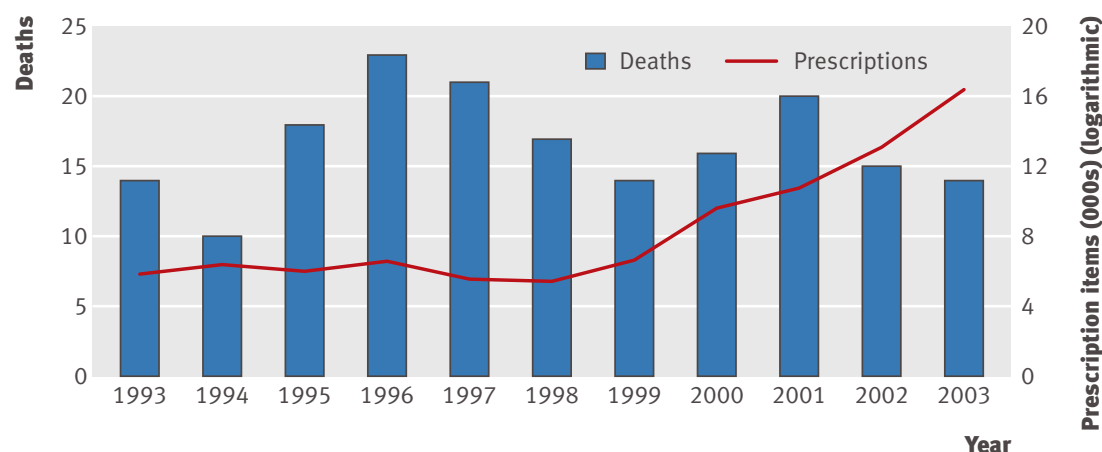

Secular trends showing deaths and prescription items for methadone, Tayside 1993-2003. Two deaths and 2116 prescription items for methadone occurred in the period January to February 2004-data included in overall analysis but not presented in figure

structured psychosocial support is recommended alongside explicit pharmacological support: supervised consumption, clarity about maintenance or detoxification, and optimal dose ranges for maintenance. ${ }^{15}$ However, evidence based guidance of this sort was not available to general practitioners in the mid-1990s.

In this study, we aimed to examine the interaction of patient related factors and prescribing factors at the individual level and assess their independent impact on the risk of both all cause mortality and drug dependent cause specific mortality in a primary care setting in a defined geographical population.

\section{METHODS}

\section{Study design and patients}

We identified people resident in Tayside, Scotland, who were registered with a general practitioner and were prescribed and dispensed liquid methadone between January 1993 and February 2004. Every person registered with a general practitioner in Tayside is assigned a 10 digit unique patient identifier, the Community Health Index number used in all encounters with the NHS. This number, which includes the person's date of birth, allows linkage of health related datasets, providing a unique resource combining information on dispensed prescribing with detailed clinical data at the level of the individual patient.

\section{Procedures}

We collected data on age, sex, and postcode for each patient who was dispensed a liquid methadone prescription from the Community Health Index number register. We used the number to link these records to all dispensed prescribing and to standard morbidity register records for admission to hospital or to a psychiatric unit. In addition, we made linkages to General Register Office mortality data and to laboratory datasets relating to urine testing for opiates and other drugs. We followed standard operating procedures at the Health Informatics Centre, University of Dundee, to ensure anonymisation of the dataset (www.dundee.ac. uk/hic/).
We used census data from 2001 to calculate a Carstairs score and subsequent category for socioeconomic status for each person on the basis of their home postcode. ${ }^{16}$ We derived a Charlson comorbidity index, which is a validated prognostic indicator for comorbidity, from each person's standard morbidity register record by using the ICD-9 and ICD-10 (international classification of diseases, ninth and 10th revisions) codes in the hospital admission records. ${ }^{1718} \mathrm{We}$ also examined the encashed prescribing records and flagged the Charlson disease groups for people who were receiving drugs for respiratory disease, AIDS, peptic ulcers, cancer, metastatic tumours, diabetes, myocardial infarction, connective tissue disorders, and dementia. We categorised Charlson index scores into three groups with low (0), medium (1 to 2$)$, and high $(\geq 3)$ morbidity.

Each record of a prescription for methadone contained details on the patient's Community Health Index number; the date of prescription; the dose, quantity, strength, and type of methadone; and the general practitioner and practice where the prescription was issued. We calculated the length of methadone treatment from the number of days between the first and last prescriptions and the coverage of the last prescription. We calculated the mean dose of methadone from the total days' coverage for each person (number of days at prescribed amount for each prescription) and the total amount prescribed. We categorised people as overusing methadone if the length of treatment was shorter than the total coverage of the prescribed prescriptions. We flagged patients as "on treatment" if their last methadone prescription was within three months of their date of death or the end of the study period. We defined a "break" in methadone treatment if a discontinuation in prescription of methadone of 90 days or more occurred. In accordance with UK prescribing recommendations, we categorised people who were below, within, and above the recommended methadone maintenance range of $60 \mathrm{mg}$ to $120 \mathrm{mg}$ daily, and fitted this as a binary variable with $\geq 60 \mathrm{mg}$ as the cut-off point. $^{19}$

We examined prescribing records for other drugs and recorded any patient who was prescribed a drug from the hypnotic or anxiolytic class as receiving benzodiazepines. We recorded drugs used for psychoses and related disorders as antipsychotics and also recorded use of antidepressants and opioid analgesics.

We calculated the total number of prescriptions issued from each practice from the prescribing records. We then grouped practices into quarters on the basis of the number of methadone prescriptions issued and assigned each person the value for the last practice to issue methadone. We included this variable in the survival analysis to represent the volume of methadone prescribing by practice.

Our main outcome measure was all cause mortality recorded on the General Registry Office death certificate or on the Community Health Index number register held by Tayside Health Board. 
Table 1|Characteristics of cohort, according to whether patients were alive or died. Values are numbers (percentages)

\begin{tabular}{|c|c|c|c|}
\hline Characteristics & $\begin{array}{l}\text { Patients alive who } \\
\text { took methadone } \\
(\mathrm{n}=2197)\end{array}$ & $\begin{array}{l}\text { Patients who died } \\
\text { taking methadone } \\
\qquad(\mathrm{n}=181)\end{array}$ & Total $(n=2378)$ \\
\hline Male & $1462(67)$ & $127(70)$ & $1589(67)$ \\
\hline \multicolumn{4}{|l|}{ Age (years): } \\
\hline $16-19$ & 241 (11) & $9(5)$ & 250 (11) \\
\hline $20-29$ & $1230(56)$ & $87(48)$ & $1317(55)$ \\
\hline $30-39$ & $517(24)$ & $56(31)$ & $573(24)$ \\
\hline $40-60$ & 209 (10) & $29(16)$ & $238(10)$ \\
\hline \multicolumn{4}{|l|}{ Social class (Carstairs): } \\
\hline 1 & $27(1)$ & $4(2)$ & $31(1)$ \\
\hline 2 & $131(6)$ & $3(2)$ & $134(6)$ \\
\hline 3 & 305 (14) & $21(12)$ & 326 (14) \\
\hline 4 & $207(9)$ & $15(8)$ & $222(9)$ \\
\hline 5 & $407(19)$ & $29(16)$ & $436(18)$ \\
\hline 6 & $608(28)$ & $63(35)$ & $671(28)$ \\
\hline 7 & $490(22)$ & $42(23)$ & $532(22)$ \\
\hline \multicolumn{4}{|c|}{ Comorbidity (Charlson index): } \\
\hline 0 & $1982(90)$ & $96(53)$ & $2078(87)$ \\
\hline $1-2$ & $157(7)$ & $27(15)$ & $184(8)$ \\
\hline$\geq 3$ & $58(3)$ & $58(32)$ & $116(5)$ \\
\hline \multicolumn{4}{|l|}{ Mean methadone dose: } \\
\hline$<60 \mathrm{mg}$ & $1878(85)$ & $145(80)$ & $2023(85)$ \\
\hline $60-120 \mathrm{mg}$ & $345(16)$ & $36(20)$ & $381(16)$ \\
\hline$\geq 120 \mathrm{mg}$ & $6(<1)$ & $0(0)$ & $6(\ll 1)$ \\
\hline Overusing methadone & $119(5)$ & $29(16)$ & $148(6)$ \\
\hline \multicolumn{4}{|l|}{ Methadone breaks: } \\
\hline 0 & $1019(46)$ & $108(60)$ & $1127(47)$ \\
\hline 1 & $554(25)$ & $46(25)$ & $600(25)$ \\
\hline $2-3$ & $488(22)$ & $21(12)$ & 509 (21) \\
\hline$\geq 4$ & $136(6)$ & $6(3)$ & $142(6)$ \\
\hline \multicolumn{4}{|c|}{ Duration of methadone treatment: } \\
\hline$\ll 6$ months & $445(20)$ & $51(28)$ & $496(21)$ \\
\hline 6 months to 1 year & $212(10)$ & $21(12)$ & $233(10)$ \\
\hline $1-2$ years & $385(18)$ & $24(13)$ & 409 (17) \\
\hline $2-3$ years & $195(9)$ & $19(11)$ & $214(9)$ \\
\hline 13 years & $944(43)$ & $63(35)$ & $1007(42)$ \\
\hline
\end{tabular}

Time since last methadone

prescription filled:

\begin{tabular}{lccc}
\hline$\leq 1$ month & $835(38)$ & $94(52)$ & $929(39)$ \\
\hline $2-3$ months & $281(13)$ & $23(13)$ & $304(13)$ \\
\hline $4-6$ months & $207(9)$ & $9(5)$ & $216(9)$ \\
\hline$>6$ months & $874(40)$ & $55(30)$ & $929(39)$ \\
\hline Psychiatric admission & $1025(47)$ & $139(77)$ & $1164(49)$ \\
\hline Urine tests & $1764(80)$ & $93(51)$ & $1857(78)$ \\
\hline On treatment at end of follow-up & $1116(51)$ & $117(65)$ & $1233(52)$ \\
\hline Co-prescribing: & & & \\
\hline Benzodiazepines & $1634(74)$ & $160(88)$ & $1794(75)$ \\
\hline Antipsychotics & $451(21)$ & $33(18)$ & $484(20)$ \\
\hline Antidepressants & $1051(48)$ & $80(44)$ & $1131(48)$ \\
\hline Opioid analgesics & $831(38)$ & $99(55)$ & $930(39)$ \\
\hline
\end{tabular}

\section{Statistical analysis}

We report data statistics as number (percentage) of people for categorical variables and mean (SD) for continuous variables. Continuous variables that do not follow a normal distribution were tested with the Shapiro-Wilks test for skewness and reported as the median and interquartile range. We report $\chi^{2}$ tests for trend for differences in distribution of the population.

We used Cox proportional hazards models to estimate hazard ratios and 95\% confidence intervals for each unadjusted and adjusted covariate in relation to all cause mortality and cause specific mortality. We included covariates in the multivariate model if we deemed them to be of clinical significance or if they had a univariable $\mathrm{P}$ value below 0.2 . We assessed the proportional hazards assumption by using trend tests of the Schoenfeld residuals; those that failed the assumption or were deemed to be time dependent were entered as continuous time dependent covariates. ${ }^{20}$ Hazard ratios for variables treated as time dependent covariates vary over time, so we report them at the median follow-up time. We followed up patients until time of death or the end of the study period. We used Stata version 9 for all statistical analyses.

\section{Sample size}

Our sample size calculation assumed an estimate of multiple drug use of $65 \%$ in drug related fatalities, ${ }^{4}$ enabling us to detect a difference of $13 \%$ between those who died from methadone and comparators who did not die while taking methadone with a sample size of 1500 people (120 deaths with $82 \%$ power, 150 deaths with $90 \%$ power, and two sided $5 \%$ significance level).

\section{RESULTS}

\section{Descriptive statistics}

A cohort of 2378 people were prescribed and dispensed methadone during the 12 year study - a total of 12037 person years with a median follow-up of 4.38 (interquartile range 1.92-8.12) years. Table 1 shows the descriptive statistics for the cohort. Sixty five per cent were aged under 30 years, and more than half were from the lowest socioeconomic groups (Carstairs categories 6 and 7). More than $40 \%$ of patients were prescribed methadone for more than three years; $1233(52 \%)$ were still on treatment at the end of follow-up, which was either the date of death or the end of the study.

Almost half of the cohort had a record of psychiatric admission on the standard morbidity register, and coprescription of benzodiazepines, antipyschotics, antidepressants, and opioid analgesics was high (table 1). Almost four fifths of the patients had at least one urine test, and a minority had evidence of taking a mean dose of methadone higher than that recommended (table 1). The mean dose of methadone calculated across each person's prescriptions ranged from $1.7 \mathrm{mg}$ to $200 \mathrm{mg}$. The mean dose was lower than the recommended adequate maintenance range of $60-120 \mathrm{mg}$ daily for 2023 (85\%) people, within this range for $349(15 \%)$ people, and above $120 \mathrm{mg}$ for six people. The median individual mean dose was 40 (interquartile range 28-51) mg. 
Cause of death and methadone prescriptions over time During the 12 year study period, 181 (8\%) people died. The number of deaths remained constant despite the increase in methadone prescription items from 5852 in 1993 to 16379 in 2003, the last full year for which data were available (figure). Cause of death was available in $166(92 \%)$ of these people from their General Registry Office record. The remaining 15 people were identified as dead from the Community Health Index number register, but as no General Registry Office record was available we could not ascertain cause of death. Codes that relate to "drug dependence" were recorded as the principal cause in $60(33 \%)$ people. Table 2 summarises the other principal causes of death.

\section{Univariable and multivariable associations with all cause mortality}

After adjustment for significant covariates, increasing comorbidity, overuse of methadone higher than recommended, and history of psychiatric admission were all associated with an increase in all cause mortality (table 3). Longer duration of methadone use, increasing time since last methadone prescription was filled, and history of having urine testing were protective in relation to all cause mortality, but "breaks" in receiving methadone and co-prescription of drugs were not associated once fitted to the multivariable model (table 3). Variables not included after unadjusted analysis were male sex, use of benzodiazepines, and volume of methadone prescribing by practice.

\section{Univariable and multivariable associations with cause specific mortality}

When we assessed the $60(33 \%)$ people who had a "drug related" death attributable on their General Registry Office death certificate, the same explanatory variables that were protective in relation to all cause mortality persisted-namely, longer duration of methadone use, increasing time since last methadone prescription was filled, and history of having urine testing (table 4). Similarly, history of psychiatric admission remained independently associated with increased risk of drug dependent cause specific mortality. Of note, co-prescribing of benzodiazepines was now strongly associated, whereas prescription of

Table 2 | Documented cause of death from General Registry Office (GRO) death certificate $(n=166)$

\begin{tabular}{lc} 
Recorded cause of death & No (\%) \\
Drug dependence/related & $60(36)$ \\
\hline Endocarditis, cardiovascular & $11(7)$ \\
\hline HIV related & $14(8)$ \\
\hline Cancer & $20(12)$ \\
\hline Pneumonia and related & $5(3)$ \\
\hline Accidents, trauma, self harm & $13(8)$ \\
\hline Liver disease, hepatitis C & $9(5)$ \\
\hline Other & $34(20)$
\end{tabular}

15 patients were identified as dead from Community Health Index number register, but as no GRO record was available cause of death could not be ascertained. antidepressants and antipsychotics seemed to be protective in relation to drug related death (table 4).

\section{DISCUSSION}

This primary care based study has characterised the population of people engaged with a methadone programme as being predominantly young men from a lower socioeconomic background. ${ }^{2122}$ Psychiatric admission in the 12 years of follow-up occurred in almost half the cohort, co-prescribing of benzodiazepines occurred in three quarters of the cohort, and coprescribing of antidepressants occurred in half. The population could thus be classified as a vulnerable and deprived group.

The overall mortality of $8 \%$ in the cohort during the 12 year study period is slightly above the annual mortality rate of four to five per 100000 described in a previous Scottish study. ${ }^{12}$ Clear signals emerge in relation to safe prescribing and monitoring of methadone maintenance treatment in primary care, but caution is needed in that these associations may not be causal because of the nature of this observational study. ${ }^{23}$ Overuse of methadone may be a marker of less rigorous follow-up and communication between prescribing general practitioners and dispensing community pharmacists. Alternatively, overuse may be a marker for people who have dispersed the drug to others. UK guidance emphasises that methadone maintenance treatment needs a coordinated multidisciplinary approach. ${ }^{1924}$ Although only a relatively small proportion of the people used a higher than recommended dose of methadone, their relative risk of death was more than one and a half times that of people who took the correct dosage. Not unexpectedly, comorbidity remains an independent risk factor in relation to all cause mortality in the cohort, and the strongest association was for patients with a history of psychiatric admission (table 3). In terms of protective factors, longer duration of treatment, increasing time since last methadone prescription, and a history of involvement in urine testing programmes (irrespective of the result) were associated with a reduced risk of all cause mortality. These are likely to be markers of people who are stabilised on maintenance treatment and engaged in monitoring procedures or who have successfully completed a methadone treatment reduction programme.

We found substantial under-dosing with methadone; $84 \%$ of the cohort were receiving a mean dose that was less than the recommended 60-120 mg advised by UK Advisory Council on the Misuse of Drugs and National Institute for Health and Clinical Excellence (NICE). ${ }^{1924}$ This finding is consistent with comparative data in other countries. ${ }^{25}$ Commentators suggest that some proponents of methadone are strong advocates of higher doses of methadone in terms of retention and reduction of heroin usage. ${ }^{26}$ Evidence from randomised controlled trials comparing different methadone dosages supports this view, but the findings in relation to mortality from overdose, although favouring higher doses of methadone $>75 \mathrm{mg}$ daily versus $5-55 \mathrm{mg}$ daily), are based on a very small 
Table 3|Univariable and multivariable associations between covariates and all cause mortality

\begin{tabular}{|c|c|c|}
\hline Cohort characteristic & $\begin{array}{l}\text { Unadjusted hazard ratio } \\
\qquad(95 \% \mathrm{Cl})\end{array}$ & $\begin{array}{c}\text { Adjusted hazard ratio } \\
(95 \% \mathrm{Cl})\end{array}$ \\
\hline Male sex & $1.06(0.77$ to 1.45$)$ & NA \\
\hline Age (per year) & $1.04(1.02 \text { to } 1.05)^{\star}$ & $1.00(0.98$ to 1.01$)$ \\
\hline \multicolumn{3}{|l|}{ Social class (Carstairs): } \\
\hline 1 (reference category) & 1.0 & 1.0 \\
\hline 2 & $0.16(0.04 \text { to } 0.73)^{\star}$ & 0.18 (0.04 to 0.82$)^{\star}$ \\
\hline 3 & 0.48 (0.16 to 1.40$)$ & $0.52(0.17$ to 1.54$)$ \\
\hline 4 & 0.49 (0.16 to 1.49$)$ & $0.45(0.15$ to 1.41$)$ \\
\hline 5 & $0.41(0.14$ to 1.17$)$ & $0.36(0.12$ to 1.04$)$ \\
\hline 6 & $0.62(0.22$ to 1.70$)$ & 0.46 (0.16 to 1.28$)$ \\
\hline 7 & 0.54 (0.19 to 1.51$)$ & 0.52 (0.18 to 1.76$)$ \\
\hline \multicolumn{3}{|l|}{ Comorbidity (Charlson index): } \\
\hline 0 (reference category) & 1.0 & 1.0 \\
\hline $1-2$ & $2.85(1.86 \text { to } 4.37)^{\star}$ & $1.08(1.02 \text { to } 1.14)^{*} \dagger$ \\
\hline$\geq 3$ & $6.58(4.72 \text { to } 9.19)^{\star}$ & $1.20(1.15 \text { to } 1.26)^{*} \dagger$ \\
\hline Mean methadone dose $\geq 60 \mathrm{mg}$ & $1.54(1.07 \text { to } 2.23)^{\star}$ & $0.93(0.62$ to 1.39$)$ \\
\hline Overusing methadone & $3.12(2.09 \text { to } 4.64)^{\star}$ & $1.67(1.05 \text { to } 2.67)^{\star}$ \\
\hline Methadone breaks & $0.58(0.50 \text { to } 0.67)^{\star}$ & $0.93(0.78$ to 1.10$)$ \\
\hline Duration of methadone treatment (years) & $0.78(0.75 \text { to } 0.82)^{\star}$ & $0.95(0.94 \text { to } 0.96)^{*} \dagger$ \\
\hline \multicolumn{3}{|c|}{ Time since last methadone prescription filled (months): } \\
\hline$\leq 1$ (reference category) & 1.0 & 1.0 \\
\hline $2-3$ & 0.77 (0.49 to 1.22$)$ & $0.97(0.91$ to 1.02$) \dagger$ \\
\hline $4-6$ & $0.66(0.33$ to 0.1 .30$)$ & $0.91(0.84 \text { to } 0.99)^{*} \dagger$ \\
\hline$>6$ & $0.45(0.32 \text { to } 0.62)^{\star}$ & $0.70(0.66 \text { to } 0.73)^{\star} \dagger$ \\
\hline Psychiatric admission & $2.46(1.74 \text { to } 3.49)^{\star}$ & $2.47(1.67 \text { to } 3.66)^{\star}$ \\
\hline Having urine tested & $0.31(0.23 \text { to } 0.41)^{\star}$ & $0.33(0.22 \text { to } 0.49)^{\star}$ \\
\hline \multicolumn{3}{|l|}{ Co-prescribing: } \\
\hline Benzodiazepines & $1.18(0.74$ to 1.86$)$ & NA \\
\hline Antipsychotics & $0.77(0.53$ to 1.12$)$ & 0.85 (0.56 to 1.29$)$ \\
\hline Antidepressants & 0.76 (0.56 to 1.01$)$ & 0.80 (0.57 to 1.44$)$ \\
\hline Opioid analgesics & 1.33 (0.99 to 1.79$)$ & $1.17(0.84$ to 1.64$)$ \\
\hline
\end{tabular}

Final regression model mutually adjusted for all significant covariates; male sex, use of benzodiazepines, and volume of methadone prescribing by practice were assessed unadjusted but had no significant influence (P>0.2) and so were excluded from final model.

NA=not applicable.

${ }^{*} \mathrm{P}<0.05$.

†Variable treated as time varying coefficient in Cox regression model and hazard ratio reported at median follow-up of 4.38 years.
NICE guidelines acknowledge, ${ }^{24}$ most randomised controlled trials of methadone in the treatment of drug dependence were done in outpatient or inpatient settings or specialist treatment centres. This community based study gives a clear indication of the prescribing, monitoring, and management of these patients and the subsequent impact on all cause and drug dependent mortality.

The unique nature of this dataset in terms of record linkage provides evidence that recommendations on best practice improve patients' outcomes and that the improvements that have taken place in terms of the delivery of methadone maintenance programmes in the UK are likely to reduce the risk of death in this vulnerable group of people. ${ }^{82}$ This study also provides evidence about subgroups of people, particularly those with a history of psychiatric admission, who have a higher risk of death. Similarly, for general practitioners who are prescribing methadone, monitoring of urine and avoidance of co-prescribing of benziodiazepines should be implemented. The findings from this study emphasise the need for a psychosocial perspective in relation to ongoing management of people enrolled in methadone maintenance programmes. In some situations, people at higher risk (history of psychiatric illness, poor engagement with services including urine testing) might be more appropriately managed in a specialist, rather than a generalist, environment.

To avoid methadone related deaths and improve the quality of methadone prescribing, the UK Advisory Council on the Misuse of Drugs has produced guidelines that recommend a structured delivery of service with clear roles and responsibilities, particularly for the prescribing doctor, alongside psychosocial care. ${ }^{1129} \mathrm{By}$ providing clear and explicit recommendations about the prescribing and dispensing of methadone, in conjunction with an organised system of delivery, drug related mortality and morbidity are expected to be reduced. ${ }^{1430}$ However, commentators acknowledge that many of the recommendations in the guidelines are "very loosely evidence-based," ${ }^{14}$ and quality markers associated with the prescribing and delivery of methadone need to be validated and related to individual outcomes. The results of this cohort study provide evidence of the value of stabilised prescribing, regular monitoring of urine, and avoidance of co-prescribing of benzodiazepines when possible.

\section{Context of other studies}

In the context of other studies, our findings are consistent with the demographic pattern of drug related deaths occurring in young, socially deprived men. ${ }^{2122}$ The findings in relation to all cause mortality are consistent with the high mortality described in the drug outcomes research in Scotland (DORIS) study. ${ }^{31}$ Although a relatively small proportion of the Tayside population were prescribed methadone, the proportion who died during the follow-up period was substantial. The applicability of our findings in terms of methadone maintenance programmes in primary care is therefore likely to be robust. 
Co-prescribing of benzodiazepines was associated with drug related death, which supports findings that these substances, along with alcohol, are commonly found in subsequent toxicological reports of drug related deaths. ${ }^{21}$ Previous UK research showed that people prescribed methadone as well as benzodiazepines were at greater risk of overdose than patients taking methadone alone. ${ }^{32}$ More detailed toxicology reports were not available, and we are unable to report on this. Nevertheless, the high proportion of co-prescribing of benzodiazepines throughout the study period, combined with its association with drug related death, is a troublesome finding.

\section{Limitations of study}

This study has some shortcomings. The significant association of a mean dose of methadone higher than that recommended with all cause mortality could be attributed to factors other than use of a higher dose of methadone in itself-for instance, it could be a marker for more chaotic drug using behaviour or dispersion of methadone. Furthermore, in observational studies of this sort, the possibility of residual confounding may remain a problem; caution is needed when interpreting the association of organisational and prescribing factors with all cause and drug dependent cause specific mortality, and these associations should be viewed

Table 4 | Univariable and multivariable associations between covariates and drug dependent cause specific mortality

\begin{tabular}{|c|c|c|}
\hline Cohort characteristic & $\begin{array}{l}\text { Unadjusted hazard ratio } \\
(95 \% \mathrm{Cl})\end{array}$ & $\begin{array}{c}\text { Adjusted hazard ratio } \\
(95 \% \mathrm{Cl})\end{array}$ \\
\hline Male sex & $1.24(0.70$ to 2.21$)$ & NA \\
\hline Age (per year) & $0.98(0.95$ to 1.01$)$ & $1.00(0.98$ to 1.01$)$ \\
\hline \multicolumn{3}{|l|}{ Social class (Carstairs): } \\
\hline 1-4 (reference category) & 1.0 & NA \\
\hline $5-7$ & $1.12(0.63$ to 2.02$)$ & NA \\
\hline Mean methadone dose $\geq 60 \mathrm{mg}$ & $0.68(0.29$ to 1.58$)$ & NA \\
\hline Overusing methadone & $4.52(2.47 \text { to } 8.26)^{\star}$ & $1.85(0.91$ to 3.80$)$ \\
\hline Methadone breaks & $0.51(0.39 \text { to } 0.68)^{*}$ & $1.01(0.74$ to 1.40$)$ \\
\hline Duration of methadone treatment (years) & $0.76(0.69 \text { to } 0.83)^{\star}$ & $0.93(0.92 \text { to } 0.95)^{\star} \dagger$ \\
\hline \multicolumn{3}{|c|}{ Time since last methadone prescription filled (months): } \\
\hline$\leq 1$ (reference category) & 1.0 & 1.0 \\
\hline $2-3$ & $0.52(0.22$ to 1.24$)$ & $0.64(0.26$ to 1.04$)$ \\
\hline 4-6 & 0.40 (0.10 to 1.67$)$ & 0.24 (0.06 to 1.01$)$ \\
\hline$>6$ & $0.34(0.19 \text { to } 0.62)^{\star}$ & $0.02(0.00 \text { to } 0.05)^{\star}$ \\
\hline Psychiatric admission & $2.23(1.22 \text { to } 4.07)^{\star}$ & $2.41(1.25 \text { to } 4.64)^{\star}$ \\
\hline Having urine tested & $0.27(0.16 \text { to } 0.45)^{\star}$ & 0.52 (0.26 to 1.04$)$ \\
\hline \multicolumn{3}{|l|}{ Co-prescribing: } \\
\hline Benzodiazepines & $2.73(0.85$ to 8.76$)$ & $4.35(1.32 \text { to } 14.30)^{\star}$ \\
\hline Antipsychotics & $0.18(0.056 \text { to } 0.58)^{\star}$ & $0.27(0.08 \text { to } 0.89)^{\star}$ \\
\hline Antidepressants & $0.29(0.16 \text { to } 0.53)^{\star}$ & $0.51(0.30 \text { to } 0.98)^{\star}$ \\
\hline Opioid analgesics & $0.65(0.39$ to 1.10$)$ & $0.72(0.41$ to 1.26$)$ \\
\hline
\end{tabular}

Final regression model mutually adjusted for all significant covariates; male sex, comorbidity (Charlson index), social class, mean methadone dose ( $\geq 60 \mathrm{mg}$ daily), and volume of methadone prescribing by practice were assessed unadjusted but had no significant influence on cause specific mortality $(P>0.2)$ and so were excluded from final model.

$\mathrm{NA}=$ not applicable.

${ }^{*} \mathrm{P}<0.05$.

†Variable treated as time varying coefficient in Cox regression model and hazard ratio reported at median

follow-up of 4.38 years.

\section{WHAT IS ALREADY KNOWN ON THIS TOPIC}

Randomised controlled trials have shown that methadone maintenance is an effective intervention, decreasing illicit drug use, reducing injecting behaviour, and reducing opioid related deaths

Concern exists about the safety of prescribing methadone in community settings, as methadone itself is associated with drug related deaths

\section{WHAT THIS STUDY ADDS}

Overuse of methadone, history of psychiatric admission, and increased comorbidity were associated with all cause mortality; drug dependent deaths were associated with coprescription of benzodiazepines and history of psychiatric admission

History of urine testing, longer duration of use of methadone, and increasing time since last filled prescription were all associated with a reduced risk of death

Important elements in the process of care when providing methadone maintenance in the community may influence each person's risk of death.

principally as hypothesis generating. We could not collect data on cause of death for $15(8 \%)$ of the total cohort who died and acknowledge that documented cause of death may have been difficult to ascertain or attribute for some people. Other shortcomings of the study relate to the limited details of practice arrangements regarding initial assessment, supervised consumption, and counselling arrangements. As a previous national study of drug related deaths found, the completeness of primary care records in relation to antecedent management is often poor. ${ }^{24}$ Lastly, our cut-off point of three months or more since the filling of the last prescription is likely to be conservativemany people will have stopped taking methadone by this time.

\section{Implications for methadone programmes}

This cohort did not have a record of psychological, quality of life, or other patient centred indices of wellbeing. Other community based studies have interviewed participants and obtained these types of data, albeit in a more selected sample. ${ }^{334}$ The interaction of psychological wellbeing, history of psychiatric admission, and the impact of psychosocial support alongside methadone prescribing and monitoring needs further study. In terms of improving the delivery of methadone maintenance programmes in primary care, paper based guidance may no longer be sufficient. Health information technology systems have been shown to improve quality of care by increasing adherence to guideline based recommendations, enhancing surveillance and monitoring, and decreasing the incidence of drug errors. ${ }^{35}$ Similarly, computerised clinical decision support systems that are focused more on clinical decision making and provide support on drug prescribing (dose, duration, and appropriateness), drug monitoring, and drug interactions may have a role. 
The requirement of an evidence based approach to methadone maintenance is well suited to implementation by means of such support systems, particularly in relation to coordination of care and multidisciplinary working. ${ }^{636}$ Computerised clinical decision support systems would also support alternative forms of opioid replacement treatment such as buprenorphine. ${ }^{37}$

\section{Conclusions}

This community based study shows that important elements in the process of care when providing methadone maintenance are likely to influence each patient's risk of death. Prescribing of methadone could be improved, particularly as regards dosage, co-prescribing of benzodiazepines, and monitoring. Further research is needed into health information technology systems that provide structure to the planning, coordination, and monitoring needed for an effective methadone maintenance programme in primary care. ${ }^{35}$

We thank Philip Thompson, Alison Bell, Sarah McGarroll, and Duncan Heather of the Health Informatics Centre, University of Dundee, for anonymisation, record linkage, and other procedural assistance in preparing the dataset; Karen Melville for advice about dispensing abbreviations and arrangements of methadone prescriptions; Peter Donnan for statistical advice; and Alex Baldacchino and Deborah Zador for helpful comments on the manuscript

Contributors: All authors were responsible for writing the study protocol and obtaining funding. CMcC did the statistical analysis. TF wrote the firs draft of the paper, and all authors commented on subsequent drafts. TF is the guarantor.

Funding: Programme support grant of the Chief Scientist's Office, NHS Scotland and EastRen project grant 116-05. CMcC was supported as an $M R C$ research training fellow in health services research. The funders had no input into the study design; the collection, analysis, and interpretation of data; the writing of the report; or the decision to submit the article for publication. The investigators are fully independent of the funders and have not used a third party to write or prepare the manuscript.

Competing interests: None declared.

Ethical approval: The Tayside Committee on Medical Research Ethics and the Caldicott Guardian approved the study.

1 ISD Scotland. Drug misuse statistics Scotland 2002. Edinburgh: I SD Publications,

2003 (available at www.drugmisuse.isdscotland.org/publications/ 02bull/02bullb.htm).

2 Department of Health. Statistics for the regional drug misuse databases. London: Department of Health, 2001.

3 Krantz MJ, Mehler PS. Treating opioid dependence: growing implications for primary care. Arch Intern Med 2004;164:277-88.

4 Gossop M, Stewart D, Treacy S, Marsden J. A prospective study of mortality among drug misusers during a 4-year period after seeking treatment. Addiction 2001;97:39-47.

5 Mattick RP, Breen C, Kimber J, Davoli M. Methadone maintenance therapy versus no opioid replacement therapy for opioid dependence. Cochrane Database Syst Rev 2003; (2):CD002209.

6 Ward J, Hall W, Mattick RP. Role of maintenance treatment in opioid dependence. Lancet 1999;353:221-6.

7 Sporer KA. Strategies for preventing heroin overdose. BMJ 2003;326:442-4.

8 Strang J, Sheridan J. Effect of national guidelines on prescription of methadone: analysis of NHS prescription data, England 1990-2001. BMJ 2003;327:321-2.

9 Morgan O, Griffiths C, Hickman M. Association between availability of heroin and methadone and fatal poisoning in England and Wales 1993-2004. Int J Epidemiol 2006;35:1579-85.

10 Weinrich M, Stuart M. Provision of methadone treatment in primary medical care practices: review of the Scottish experience and implications for US policy. JAMA 2003;283:1343-8.
11 Advisory Council on the Misuse of Drugs. Reducing drug related deaths. London: Stationery Office, 2000.

12 Squires T, Robertson R, Jay J, Robinson A, Bruce M. National Confidential Enquiry into Methadone Related Deaths (Scotland) 2000, 2000. www.crag.scot.nhs.uk/topics/mhealth/NCEMRD.doc.

13 Hickman M, Madden P, Henry J, Baker A, Wallace C, Wakefield J, et al. Trends in drug overdose deaths in England and Wales 1993-98: methadone does not kill more people than heroin. Addiction 2003;98:419-25.

14 Keen J. Managing drug misuse in general practice. $B M J$ 1999;318:1503-4.

15 Royal College of General Practitioners. RCGP Substance Misuse Unit. www.rcgp.org.uk/practising_as_a_gp/substance_misuse.aspx

16 Carstairs V, Morris R. Deprivation and health in Scotland. Health Bull 1990;48:162-75.

17 Deyo RA, Cherkin DC, Ciol MA. Adapting a clinical comorbidity index for use with ICD-9-CM administrative databases. / Clin Epidemiol 1992;45:613-9.

18 Sundararajan V, Henderson T, Perry C, Muggivan A, Quan H, Ghali WA. New ICD-10 version of the Charlson comorbidity index predicted in-hospital mortality. J Clin Epidemiol 2004;57:1288-94.

19 Department of Health, Scottish Office Department of Health, Welsh Office, Social Services Northern Ireland. Drug misuse and dependence-guidelines on clinical management. London: Stationery Office, 1999.

20 Bradburn MJ, Clark TG, Love SB, Altman DG. Survival analysis part III: multivariate data analysis-choosing a model and assessing its adequacy and fit. Br J Cancer 2003;89:605-11.

21 Zador D, Kidd B, Hutchinson S, Taylor A, Hickman M, Fahey T, et al. National investigation into drug related deaths in Scotland, 2003. Edinburgh: Scottish Executive, 2005.

22 Oliver P, Keen J, Mathers N. Deaths from drugs of abuse in Sheffield 1997-1999: what are the implications for GPs prescribing to heroin addicts? Fam Pract 2002;19:93-4

23 Grimes DA, Schulz KF. Bias and causal associations in observational research. Lancet 2002;359:248-52.

24 National Institute for Health and Clinical Excellence. Methadone and buprenorphine for the management of opioid dependence. London: NICE, 2007.

25 Lawrinson P, Ali R, Buavirat A, Chiamwongpaet S, Dvoryak S, Habrat B, et al. Key findings from the WHO collaborative study on substitution therapy for opioid dependence and HIV/AIDS. Addiction 2008;103:1484-92.

26 Gossop M. Maintenance treatments across countries. Addiction 2008:103:1493-4

27 Faggiano F, Vigna-Taglianti F, Versino E, Lemma P. Methadone maintenance at different dosages for opioid dependence. Cochrane Database Syst Rev 2003;(3):CD002208.

28 Keen J, Oliver P, Rowse G, Mathers N. Does methadone maintenance treatment based on the new national guidelines work in a primary care setting? Br J Gen Pract 2003;53:461-7.

29 National Prescribing Centre. The management of opioid dependence. MeReC Bulletin 2002;12(4):13-6.

30 Hall W, Zador D. Challenge of reducing drug-related deaths. Lancet 2000;356:7-8.

31 Bloor M, Gannon M, Hay G, Jackson G, Leyland AH, McKeganey N. Contribution of problem drug users' deaths to excess mortality in Scotland: secondary analysis of cohort study. BMJ 2008;337:a478.

32 Man LH, Best D, Gossop M, Stillwell G, Strang I. Relationship between prescribing and risk of opiate overdose among drug users in and out of maintenance treatment. Eur Addict Res 2004;10:35-40.

33 Gossop M, Marsden J, Stewart D, Kidd T. The national treatment outcome research study (NTORS): 4-5 year follow-up results. Addiction 2003;98:291-303.

34 Teesson M, Mills K, Ross J, Darke S, Williamson A, Havard A. The impact of treatment on 3 years' outcome for heroin dependence: findings from the Australian treatment outcome study (ATOS). Addiction 2008;103:80-8.

35 Chaudhry B, Wang J, Wu S, Maglione M, Mojica W, Roth E, et al. Systematic review: impact of health information technology on quality, efficiency, and costs of medical care. Ann Intern Med 2006;144:742-52.

36 Stille CJ, Jerant A, Bell D, Meltzer D, Elmore JG. Coordinating care across diseases, settings, and clinicians: a key role for the generalist in practice. Ann Intern Med 2005;142:700-8.

37 Law FD, Nutt DJ. Maintenance buprenorphine for opioid users. Lancet 2003;361:634-5.

Accepted: 10 February 2009 